\title{
Voice Over Internet Protocol Performance Evaluation in 6to4 Tunneling Network
}

\author{
Alauddin Maulana Hirzan, Nazrulazhar Bin Bahaman², Whisnumurti Adhiwibowo ${ }^{3}$ \\ ${ }^{1}$ Univercatitas Semarang \\ Jln. Soekarno Hatta, Tlogosari, Semarang, 024-6702757, e-mail: maulanahirzan@usm.ac.id \\ ${ }^{2}$ Universiti Teknikal Malaysia Melaka \\ Jalan Hang Tuah Jaya, 76100 Durian Tunggal, Melaka, e-mail: nazrulazhar@utem.edu.my \\ ${ }^{3}$ Universitas Semarang \\ Jln. Soekarno Hatta, Tlogosari, Semarang, 024-6702757, e-mail: whisnu@usm.ac.id
}

\section{ARTICLE INFO}

Article history:

Received 11 June 2020

Received in revised form 16 June 2020

Accepted 27 July 2020

Available online 31 July 2020

\begin{abstract}
The condition of IPv4 network in in the exhausted state right now. Most of the Regional Internet Registry reported that their regional already in exhausted state. The IPv6 was proposed to substitute IPv4 network, but the implementation of this version cased many problems such as hardware compatibility. As temporary solution to this problem, 6to4 tunneling transition mechanism is introduced as one of many solutions. This mechanism used IPv4 network as communication media between two IPv6 networks. Thus, this kind of mechanism will affect the performance of Voice over Internet Protocol. VoIP demanded real-time communication by using UDP protocol between nodes. Unlike normal communication mode, real-time mode required data to be sent immediately ignoring the quality of data. This research evaluated the performance of 6to4 tunneling mechanism for Voice over Internet Protocol's communication between two nodes in native IPv6 networks.
\end{abstract}

Keywords: VoIP, 6to4 Tunnel, Performance Evaluation, GNS3

\section{Introduction}

Pengalamatan dengan menggunakan IPv4 adalah sebuah mekanisme di mana setiap perangkat host akan ditandai dengan alamat digital berukuran 32-bit. Pengalamatan ini terdiri dari 4 potong alamat berukuran 8-bit yang dianotasikan dengan menggunakan angka decimal dan dipisahkan dengan menggunakan anotasi titik. Pengalamatan versi ini menawarkan lebih dari 4 milyar alamat unik untuk semua penggunanya di seluruh dunia. Namun, menurut Regional Internet Registry (RIR) melaporkan bahwa daerah control mereka masing-masing telah mencapai nilai maksimum pengguna yang ditawarkan oleh IPv4. Untuk saat ini hanya RIR di daerah Afrika saja yang hampir mengalami hal serupa di alamat IPv4. Sebagai pengganti IPv4. IPv6 menyediakan system pengalamatan perangkat dengan ukuran 128-bit. Sehingga IPv6 dapat menyediakan ruangan yang lebih lebar untuk menggantikan pengalamatan IPv4. Selain itu IPv6 juga menawarkan penyederhanaan header paket data, keamanan yang lebih tinggi [1][2]. 
Dibandingkan dengan IPv4, IPv6 menawarkan $2^{128}$ alamat unik jika dibandingkan dengan IPv4. Namun, terdapat masalah lagi untuk melakukan implementasi IPv6. Mengimplementasikan IPv6 ke system topologi saat ini bukan hal yang mudah untuk dilakukan. Terdapat lebih dari 1000 perangkat jaringan yang terhubung satu sama lain, dan untuk mengganti semua perangkat tersebut tidak bisa dilakukan secara mudah [3]. Oleh karena itu, mekanisme transisi diperkenalkan untuk membantu proses transisi dari jaringan IPv4 ke IPv6[4]. Terdapat banyak sekali alternative mekanisme yang bisa digunakan tergantung dari situasi topologi. Salah satu dari mekanisme transisi yang sering digunakan adalah jaringan terowong 6to4[5].

Jaringan terowong 6to4 membuat terowongan khusus di antara jaringan IPv6 melalui jaringan IPv4. Terowongan ini digunakan sebagai jalur komunikasi di antara jaringan natif IPv6 dengan menggunakan konektivitas IPv4[6]. Agar terowong 6to4 terbentuk diperlukan setidaknya dua router khusus 6to4 untuk membantu proses encapsulasi data IPv6 dengan datagram IPv4. Figur di bawah ini merupakan topologi sederhana dari jaringan terowong 6to4:

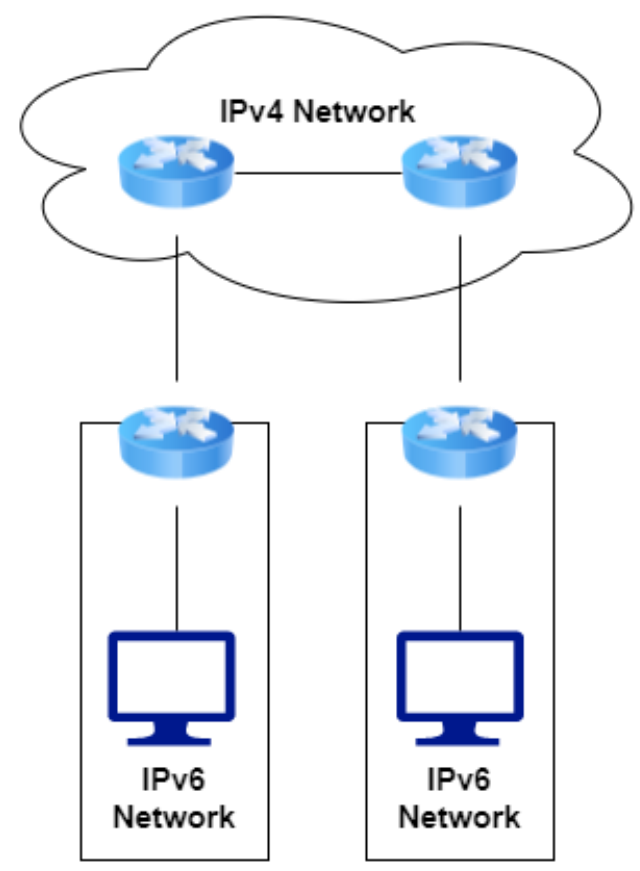

Figur 1. Ilustrasi Jaringan Terowongan 6to4

Figur 1 di atas menjelaskan bagaimana jaringan natif IPv6 (kiri bawah) dapat berkomunikasi dengan jaringan IPv6 lainnya (kanan bawah) dengan menggunakan jaringan IPv4. Router 6to4 di masing-masing jaringan IPv6 memiliki peran untuk melakukan proses encapsulasi dan dekapsulasi agar bisa melakukan transmisi data di jaringan IPv4. Dikarenakan oleh meknisme inilah, kinerja aplikasi yang memerlukan konektivitas jaringan akan mengalami penurunan khususnya untuk aplikasi real-time seperti VoIP. Voice over Internet Protocol merupakan teknologi yang mengizinkan komunikasi suara maupun video dengan menggunakan jaringan internet layaknya telelpon pada umumnya [7]. Berbeda dengan surat elektronik maupun pesan instan, data VoIP harus dikirim sesegera mungkin sehingga memiliki kemungkinan akan kerusakan selama transmisi data berlangsung. Sehingga VoIP harus berjalan di atas protocol RTP maupun RTCP agar bisa melakukan monitoring kualitas komunikas dan Quality of Service (QoS) jaringan. Selain itu, protocol RTP memiliki peran untuk membawa data media ke tujuan. Protokol-protokol yang digunakan ini memiliki kemungkinan akan penurunan kualitas di jaringan terorongan 6to4 khususnya jumlah telepon aktif yang dapat diatur oleh jaringan tersebut.

Voice Over Internet Protocol Performance Evaluation in 6to4 Tunneling Network (Alauddin 
Terdapat beberapa penelitian yang melakukan evaluasi mengenai kinerja terowongan 6to4 khususnya untuk protocol TCP dan UDP. Evaluasi kinerja terowongan 6to4 di system operasi berbasiskan Windows menunjukkan bahwa terdapat perbedaan yang signifikan dalam hal delay di jaringan teroworngan 6to4[8]. Evaluasi dalam tingkat aplikasi untuk jaringan terowong 6to4 menunjukkan bahwa dalam hal aplikasi HTTP dan komunikasi suara, mekanisme ini memiliki kinerja mendekati jaringan natif[9]. Sedangkan evaluasi kinerja untuk aplikasi realtime di jaringan 6to4 menunjukkan bahwa terjadi penurunan kualitas jika dibandingkan dengan mekanisme Dual Stack. Penurunan kinerja ini terjadi karena proses enkapsulasi di router 6to4 jika dibandingkan dengan Dual Stack yang menggunakan mekanisme parallel dalam pengiriman datanya[10]. Proses penilaian Round Trip Time (RTT) jaringan 6to4 dengan menggunakan protocol UDP dan TCP di lingkungan terkontrol menunjukkan bahwa terowongan 6to4 memiliki kinerja yang hamper sama dengan jaringan ISATAP[11]. Evaluasi kinerja di jaringan 6to4 dengan menggunakan Optimized Network Engineering Tools menunjukkan bahwa IPv4 mengalami banyak kehilangan paket dibandingkan dengan jaringa 6to. Sedangkan kinerja dari 6to4 sendiri mendekati jaringan IPv6[12].

Berdasarkan penelitian-penelitian ini, Sebagian besar dari mereka menyatakan bahwa jaringan 6to4 memiliki kinerja mendekati IPv6. Namun sebagian besar dari penelitian yang dilakukan oleh mereka masih sebatas dan hanya terfokuskan ke tingkat transmisi saja di protocol TCP dan UDP. Sedangkan penelitian di tingkat aplikasi real-time masih belum banyak dilakukan. Oleh karena itu, penelitian ini memiliki tujuan untuk melakukan evaluasi kinerja jaringan 6to4 dengan memanfaatkan SIP Call Generator dan analisis jaringan dengan menggunakan Wireshark.

\section{Research Method}

Dalam melakukan penilitian diperlukanlah data utama sebagai objek penelitian. Data-data utama yang digunakan untuk proses evaluasi ini didapatkan dengan cara eksperimen tertutup. Ketika proses pengumpulan data dilakukan, sebuah alat atau tool untuk membuat telepon berbasiskan SIP digunakan. Selama proses ini berlangsung, Wireshark akan melakukan penangkapan paket-paket data ini untuk di analisis lebih lanjut. Figur di bawah merupakan topologi/layout dari eksperimen yang akan dilakukan:

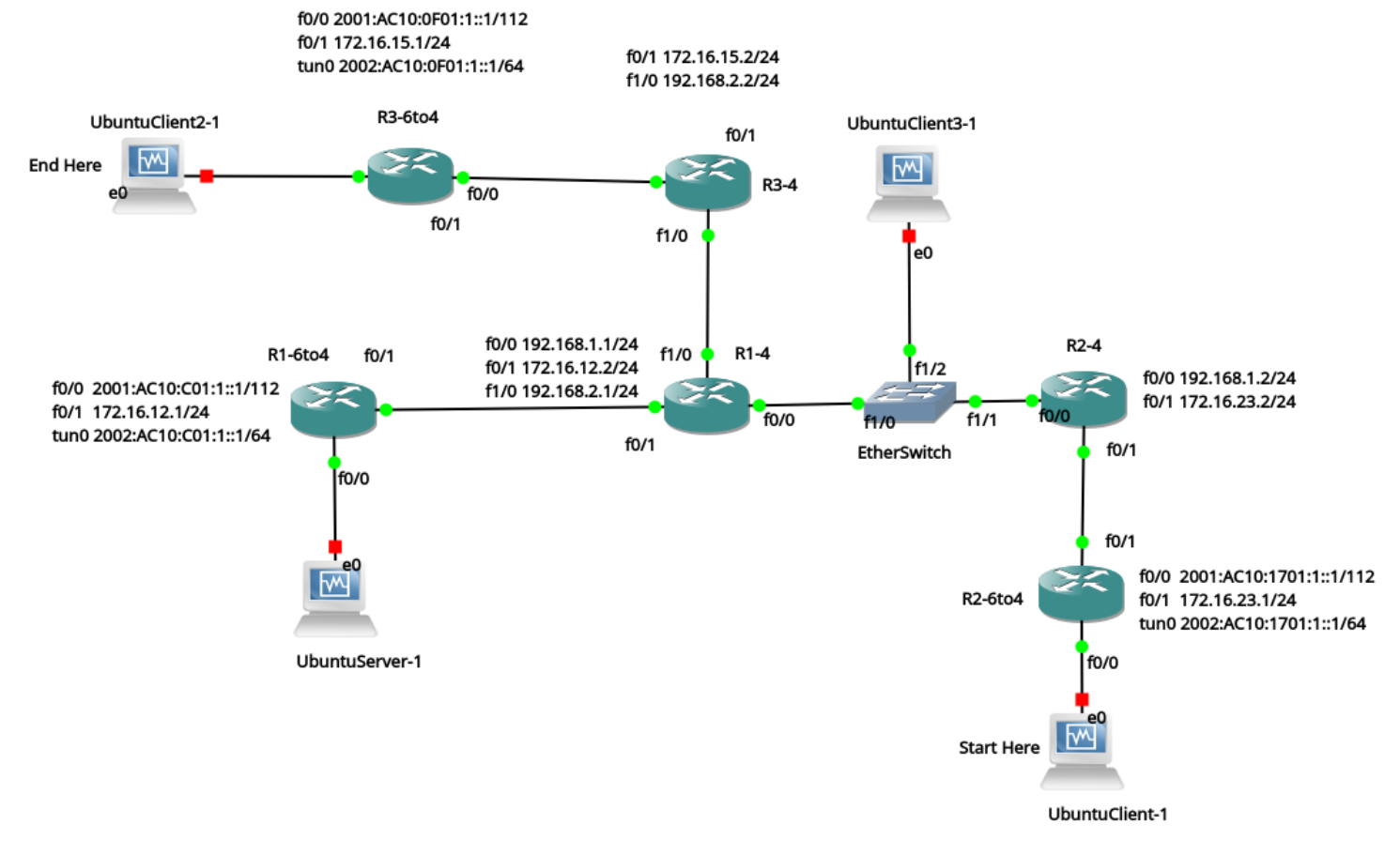

TRANSFORMATIKA Vol. 18, No. 1, July $2020: 108-113$ 
Figure 2. Topologi Eksperimen Penangkapan Data

Figur 2 di atas menjelaskan topologi eksperiment dari jaringan 6to4. Konfigurasi topologi ini memiliki tambahan router yang di mana pengirim dan penerima telepon terhubung dengan router yang berbeda. Secara sederhana, terdapat 2 perangkat klien, 1 perangkat peladen, dan 1 perangkat monitor. Peladen memiliki peran sebagai penyedia layanan SIP sehingga kedua perangkat klien harus didaftarkan ke peladen agar bisa dihubungi dan perangkat monitoring memiliki peran sebagai penangkap dan analisis aliran data VoIP.

Tabel berikut ini merupakan konfigurasi scenario dari eksperimen yang dilakukan:

Table 1. Experiment Configuration and Scenario

\begin{tabular}{|c|c|c|}
\hline Durasi Panggilan (s) & $\begin{array}{c}\text { Tingkat Generasi } \\
\text { (Panggilan/s) }\end{array}$ & Estimasi Total Panggilan \\
\hline \multirow{3}{*}{30} & 1 & 30 \\
\cline { 2 - 3 } & 5 & 150 \\
\cline { 2 - 3 } & 10 & 300 \\
\hline \multirow{3}{*}{60} & 1 & 60 \\
\cline { 2 - 3 } & 5 & 300 \\
\cline { 2 - 3 } & 10 & 600 \\
\hline \multirow{3}{*}{90} & 1 & 90 \\
\cline { 2 - 3 } & 5 & 450 \\
\hline
\end{tabular}

Tabel 1 di atas menjelaskan scenario eksperimen yang dilakukan dengan menggunakan SIP Call Generator. Panggilan yang dibuat di eksperimen dalam waktu 30, 60, dan 90 detik dengan tingkat generasi yang berbeda. Tingkat generasi panggilan dikonfigurasikan mulai dari 1 panggilan per detik, 5 panggilan per detik, dan 10 panggilan per detik. Dengan total 9 skenario yang akan dilakukan. Klien pertama akan melakukan inisailisasi panggilan dalam waktu tertentu, dan selama waktu itu juga analisis akan dilakukan.

\section{Results and Analysis}

Berdasarkan informasi dari penelitian yang didapatkankan, berikut ini adalah hasil analisis dari panggilan yang dibuat untuk jaringan terowongan 6to4:

Table 2. Hasil dari Penelitian

\begin{tabular}{|c|c|c|c|c|c|c|}
\hline \multirow{2}{*}{$\begin{array}{c}\text { Durasi } \\
\text { Panggilan }\end{array}$} & \multirow{2}{*}{$\begin{array}{l}\text { Tingkat } \\
\text { Generasi }\end{array}$} & \multicolumn{2}{|c|}{ Status Panggilan } & \multirow{2}{*}{$\begin{array}{c}\text { Jumlah } \\
\text { Panggilan }\end{array}$} & \multicolumn{2}{|c|}{ Persentasee } \\
\hline & & Sukses & Gagal & & Sukses & Gagal \\
\hline \multirow{3}{*}{30} & 1 & 29 & 0 & 29 & $100 \%$ & $0 \%$ \\
\hline & 5 & 144 & 2 & 146 & $99 \%$ & $1 \%$ \\
\hline & 10 & 150 & 149 & 299 & $50 \%$ & $50 \%$ \\
\hline \multirow{3}{*}{60} & 1 & 59 & 0 & 59 & $100 \%$ & $0 \%$ \\
\hline & 5 & 295 & 1 & 296 & $100 \%$ & $0 \%$ \\
\hline & 10 & 303 & 292 & 595 & $51 \%$ & $49 \%$ \\
\hline \multirow{3}{*}{90} & 1 & 87 & 0 & 87 & $100 \%$ & $0 \%$ \\
\hline & 5 & 290 & 4 & 294 & $99 \%$ & $1 \%$ \\
\hline & 10 & 461 & 434 & 895 & $52 \%$ & $48 \%$ \\
\hline
\end{tabular}


Tabel 2 di atas menjelaskan hasil dari proses pembuatan panggilan dari klien 1 ke klien 2 melalui jaringan terowong 6to4. Berdasarkan table di atas, tingkat kesuksesann dari panggilan yang dibuat dengan tingkat generasi 1 panggilan per detik mencapai $100 \%$. Namun tingkat kinerja ini mengalami penurunan ketika tingkat generasi panggilan dinaikkan menjadi 5 panggilan per detik. Penurunan kualitas panggilan ini tidak terjadi secara drastic, namun hanya mencapai $1 \%$ dari total panggilan yang mengalami dropped ataupun ditolak. Penurunan ini terjadi dengan drastis mencapai 50\% dari total panggilan ketika tingkat generasi dinaikkan hingga 10 panggilan per detik. Sehingga dapat disimpulkan sementara jika jaringan terowong 6to4 hanya bisa mengatur panggilan tidak lebih dari 5 panggilan per detik. Untuk analisis lebih mendalam menggunakan Wireshark, diperlihatkan dengan fitur sebagai berikut:

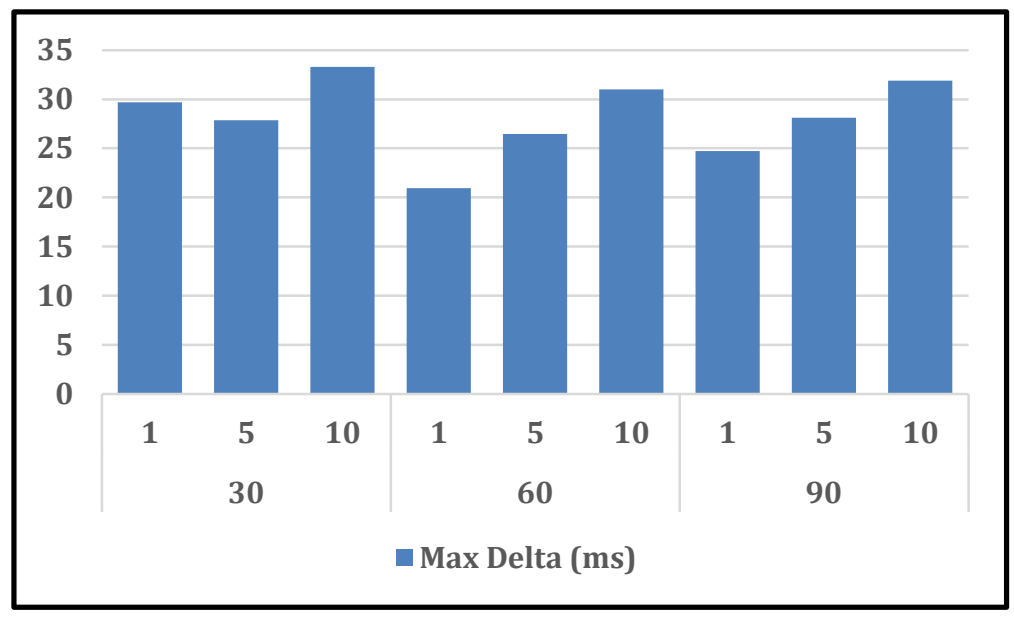

Figure 3. Jarak Antar Paket Panggilan (ms)

Figur 3 di atas adalah hasil dari maksimal jarak waktu antara dua paket RTP dipanggilan VoIP. Berdasarkan figure di atas maksimal delta tertinggi diraih oleh panggilan dengan generasi 10 panggilan per detik. Sedangkan maksimal delta paling rendah terjadi di panggilan dengan generasi 1 panggilan per detik dengan adanya pengecualian dengan scenario pertama. Terdapat kemungkinan bahwa terjadi overload ketika scenario pertama dieksekusi.

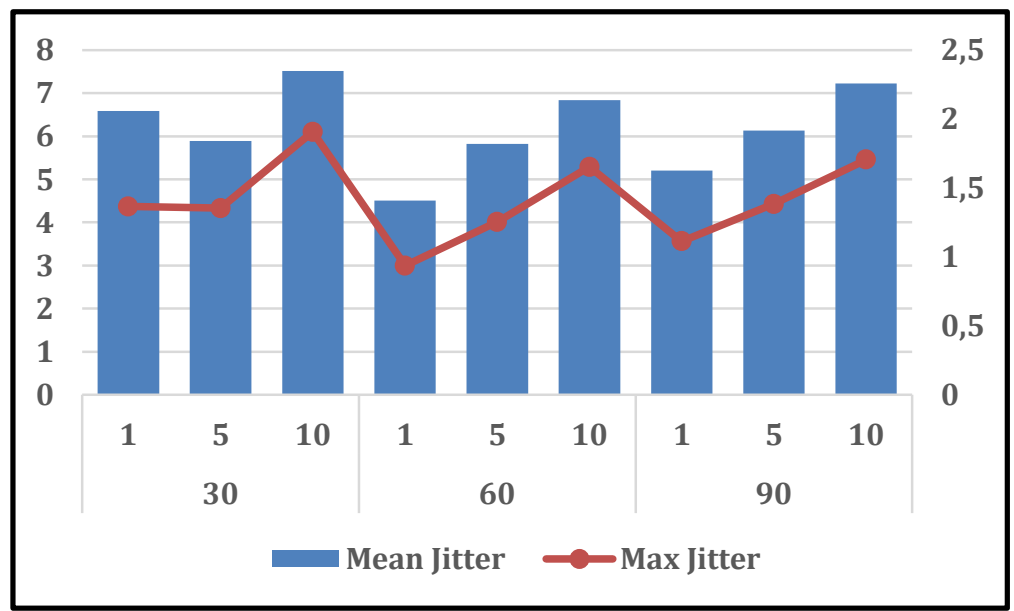

Figur 4. Hasil Jitter dari Eksperimen

Figur 4 di atas adalah hasil analisis dari Jitter panggilan dari masing-masing scenario di jaringan terowong 6to4. Rata-rata dan maksimal jitter terjadi ketika scenario dengan tingkat generasi 10 panggilan per detik di eksekusi. Berbeda dengan 1 panggilan per detik, scenario ini

TRANSFORMATIKA Vol. 18, No. 1, July $2020: 108-113$ 
memiliki rata-rata dan maksimal jitter terendah dengan pengecualian di skenario pertama dibandingkan dengan scenario lainnya. Hasil keseluruhan memiliki kesamaan, di mana scenario dengan tingkat generasi 1 panggilan per detik memiliki kinerja yang paling baik dibandingkan dengan scenario lainnya.

\section{Conclusion}

Implementasi jaringan terowong 6to4 di dunia nyata akan mempengaruhi kinerja dari aplikasi yang memerlukan komunikasi real-time khususnya aplikasi Voice over Internet Protocol. Dibandingkan dengan aplikasi pesan instan, VoIP memerlukan kinerja secara real-time sehingga integritas data yang dikirimkan tidak dipertimbangkan. Berdasarkan dari eksperimen yang telah dilakukan, jaringan terowong 6to4 hanya dapat mengatasi beban panggilan sebanyak 5 panggilan per detik. Beban panggilan yang melebihi dari 5 panggilan per detik dapat mengakibatkan panggilan tersebut akan ditolak maupun dihentikan selama transmisi. Dalam hal kinerja, semakin tinggi tingkat generasi panggilan, akan menaikkan tingkat jitter selama panggilan berlangsung. Sehingga dapat mempengaruhi kualitas panggilan secara menyeluruh.

\section{References}

[1] A. Siddiqui, "RFC 8200 - IPv6 has been standardized | Internet Society," Internet Society, 2017. .

[2] Cisco Systems, "IPv6 Addressing," Cisco Syst., vol. 6, p. 28, 2008.

[3] J. M. V. Ruiz, C. S. Cardenas, and J. L. M. Tapia, "Implementation and testing of IPv6 transition mechanisms," in 2017 IEEE 9th Latin-American Conference on Communications, LATINCOM 2017, 2017.

[4] "IPv4/IPv6 Transition," Int. J. Eng. Sci. Technol., 2012.

[5] T. P. Perumal and M. Johndoss, "IPv6 transition techniques-dual stack and tunneling," Indian J. Econ. Dev., 2017.

[6] Y. Cui et al., "Tunnel-based IPv6 transition," IEEE Internet Comput., 2013.

[7] B. Khannah, "Impact of IPv4 / IPv6 Transition Techniques on Applications Performance," no. January, pp. 374-381, 2017.

[8] D. Hadiya, R. Save, and G. Geetu, "Network performance evaluation of 6to4 and configured tunnel transition mechanisms: An empirical test-bed analysis," Int. Conf. Emerg. Trends Eng. Technol. ICETET, vol. 6, pp. 56-60, 2013.

[9] M. S. Ali and T. A. Yahiya, "Performance Analysis of Native Ipv4/Ipv6 Networks Compared to 6to4 Tunnelling Mechanism," ICOASE 2018 - Int. Conf. Adv. Sci. Eng., pp. 250-255, 2018.

[10] K. El Khadiri, O. Labouidya, N. Elkamoun, and R. Hilal, "Performance evaluation of IPv4/IPv6 transition mechanisms for real-time applications using OPNET Modeler," Int. J. Adv. Comput. Sci. Appl., vol. 9, no. 4, pp. 387-392, 2018.

[11] A. Quintero, F. Sans, and E. Gamess, "Performance Evaluation of IPv4/IPv6 Transition Mechanisms," Int. J. Comput. Netw. Inf. Secur., vol. 8, no. 2, pp. 1-14, 2016.

[12] A. Mohamed, A. K. Ahmed, A. Babiker, N. Mustafa, : Gasm, and E. Ibrahim, "Performance Evaluation of IPv4 Vs Ipv6 and Tunnelling Techniques Using Optimized Network Engineering Tools (OPNET)," IOSR J. Comput. Eng. Ver. IV, vol. 17, no. 1, pp. 2278-661, 2015. 